\title{
Promoter methylation of Wnt5a is associated with microsatellite instability and BRAF V600E mutation in two large populations of colorectal cancer patients
}

\author{
JB Rawson 1,2, M Mrkonjic ${ }^{1,2}$, D Daftary ${ }^{3}$, E Dicks4, DD Buchanan ${ }^{5}$, HB Younghusband ${ }^{4}$, PS Parfrey ${ }^{4}$, JP Young $^{5}$, \\ A Pollett ${ }^{6}$, RC Green ${ }^{4}$, S Gallinger ${ }^{1,2,3,7}$, JR McLaughlin ${ }^{2,8}$, JA Knight ${ }^{2,8}$ and B Bapat , I,2,6 $^{2}$ \\ 'Department of Laboratory Medicine and Pathobiology, University of Toronto, Toronto, Ontario, Canada M5S IA I; ${ }^{2}$ Samuel Lunenfeld Research Institute, \\ Mount Sinai Hospital, 60 Murray Street, L6-304B, Box 30, Toronto, Ontario, Canada M5G IX5; ${ }^{3}$ Ontario Familial Colorectal Cancer Registry, Cancer \\ Care Ontario, Toronto, Ontario, Canada M5G 2L7; ${ }^{4}$ Faculty of Medicine, Memorial University, St John's, Newfoundland, Canada AIC 5S7; ${ }^{5}$ Familial \\ Cancer Laboratory, Queensland Institute of Medical Research, Herston, Queensland 4006, Australia; ${ }^{6}$ Department of Pathology and Laboratory Medicine, \\ Mount Sinai Hospital, Toronto, Ontario, Canada M5G IX5; ${ }^{7}$ Department of Surgery, University of Toronto, Toronto, Ontario, Canada M5S IA I; ${ }^{8}$ Dalla \\ Lana School \\ of Public Health, University of Toronto, Toronto, Ontario, Canada M5S 2SI
}

BACKGROUND: In colorectal cancer (CRC), tumour microsatellite instability (MSI) status and CpG island methylator phenotype (CIMP) status are indicators of patient outcome, but the molecular events that give rise to these outcomes remain largely unknown. Wnt5a is a critical regulator of non-canonical Wnt activity and promoter hypermethylation of this gene has emerging prognostic roles in CRC; however the frequency and prognostic significance of this epigenetic event have not been explored in the context of colorectal tumour subtype. Consequently, we investigated the frequency and prognostic significance of Wnt5a methylation in a large cohort of MSI-stratified CRCs.

METHODS: Methylation was quantified in a large cohort of 1232 colorectal carcinomas from two clinically distinct populations from Canada. Associations were examined between methylation status and clinicopathlogical features, including tumour MSI status, BRAF V600E mutation, and patient survival.

RESULTS: In Ontario, Wnt5 a methylation was strongly associated with MSI tumours after adjustment for age, sex, and tumour location (odds ratio $(O R)=4.2$, 95\% confidence interval $(C I)=2.4-7.4, P<10^{-6}$ ) and with BRAF V600E mutation, a marker of CIMP $\left(\mathrm{OR}=12.3,95 \% \mathrm{Cl}=6.9-21.7, P<10^{-17}\right)$, but was not associated with patient survival. Concordant results were obtained in Newfoundland.

CONCLUSION: Methylation of Wnt5a is associated with distinct tumour subtypes, strengthening the evidence of an epigenetic-mediated Wnt bias in CRC.

British Journal of Cancer (201I) I 04, 1906-1912. doi:10.1038/bjc.2011.165 www.bjcancer.com

Published online 17 May 2011

(c) 20II Cancer Research UK

Keywords: colorectal cancer; methylation; Wnt; microsatellite instability

Wnt genes encode a large family of secreted glycoproteins with widespread roles in development and carcinogenesis. These proteins have classically been divided into canonical or non-canonical family members based on their ability to activate these distinct arms of the Wnt signalling network. While canonical Wnt ligands promote cell growth and proliferation by controlling cytoplasmic degradation and subsequently nuclear accumulation of $\beta$-catenin. Non-canonical Wnt ligands govern cell motility and polarity through the Wnt/calcium and/or planar cell polarity pathways, which act through a variety of intracellular mediators including calmodulin-dependent protein kinase II, protein kinase $\mathrm{C}$, and $\mathrm{c}$-Jun $\mathrm{N}$-terminal kinase. Aberrant hyperactivation of the canonical Wnt pathway is a critical tumour-initiating event in the

*Correspondence: Dr B Bapat; E-mail: bapat@lunenfeld.ca

Received I4 January 2011; revised 12 April 2011; accepted 17 April 201 I; published online 17 May 20II majority of colorectal cancers (CRCs); however, the status of noncanonical Wnt activity in cancer and its roles in carcinogenesis are poorly understood. These functions have mainly been examined through Wnt5a, the quintessential non-canonical Wnt ligand.

Wnt5a is ubiquitously expressed in normal tissues (Ying et al, 2008), but is often dysregulated in tumours (Wang et al, 2007, 2010) and has been controversially implicated in both tumour suppression and oncogenesis in addition to being recognised as a marker of both favourable and poor outcome in primary cancer. Studies supporting the former have demonstrated that $W n t 5 a$ inhibits invasion and proliferation in thyroid cancer (Kremenevskaja et al, 2005), low expression or loss of expression is prognostically unfavourable in breast cancer (Jonsson et al, 2002; Leris et al, 2005), and hemizygous mice develop lymphomas (Liang et al, 2003). On the other hand, oncogenic roles have been identified in prostate cancer, where Wnt5a promotes cell motility (Wang et al, 2010; Yamamoto et al, 2010), melanoma, where 
expression associates with tumour invasion (Weeraratna et al, 2002), and hepatocellular carcinoma, where expression is associated with poorly differentiated and invasive cell lines (Yuzugullu et al, 2009). In CRC, Wnt5a expression has been associated with favourable outcome in early stage tumours (Dejmek et al, 2005), while loss of Wnt5a expression is a hallmark of CRC-derived liver metastases (Ki et al, 2007). Collectively, these seemingly conflicting findings underscore the poorly understood functional and prognostic roles of Wnt5a in cancer.

Recent studies in leukaemia (Martin et al, 2010) and CRC (Ying et al, 2008; Ahn et al, 2011) have shown that a major mechanism for Wnt5a downregulation is promoter hypermethylation. Aberrant promoter hypermethylation is a hallmark of CRC that has a pivotal role in defining tumour subtypes; somatic methylation of the $M L H 1$ promoter causes the majority of sporadic CRC tumours with microsatellite instability (MSI), and widespread CpG island methylation defines the $\mathrm{CpG}$ island methylator phenotype (CIMP). Importantly, these methylation-dependent subtypes stratify disease outcome; MSI tumours are clinically favourable, but respond poorly to 5-fluorouracil-based chemotherapy (Ribic et al, 2003; Carethers et al, 2004), whereas CIMP tumours have complex associations with patient outcome that may depend on MSI and/or BRAF V600E status (Kim et al, 2009; Ogino et al, 2009; Dahlin et al, 2010). Despite the importance of these epigenetic modifications in defining these CRC subtypes, the specific methylation events that contribute to subtype-specific outcome has been poorly characterised.

Our previous study suggested that microsatellite stable tumours may exhibit preferential gain of non-canonical Wnt signalling through methylation of Wnt antagonists (Rawson et al, 2011). Given the importance of Wnt5a in mediating non-canonical Wnt activity and its emerging role in carcinogenesis and prognosis, we investigated the promoter methylation status of this gene in a large cohort of MSI-stratified CRCs from two distinct Canadian populations. We examined associations to patient clinicopathological features focusing on tumour subtype and patient survival in hopes that these relationships would provide further insight into subtype-specific epigenetic mediation of non-canonical Wnt signalling and would help define the prognostic role of $W n t 5 a$ methylation in CRC.

\section{MATERIALS AND METHODS}

\section{Study participants}

Probands recruited into this study were cases of primary colorectal carcinoma accrued through the population-based Ontario Familial Colorectal Cancer Registry (OFCCR) and Newfoundland Familial Colorectal Cancer Registry (NFCCR). Patient accrual, data collection, and biospecimen collection procedures at the OFCCR have been previously detailed (Newcomb et al, 2007). Briefly, Ontario residents diagnosed with pathology-confirmed CRC between the ages of 20 and 74 years from 1997 to 2000 were eligible for recruitment. Clinical data were abstracted from consenting patients through several self-administered questionnaires and cancer-related medical records. Pedigrees were constructed from family history data and used to assess familial risk status according to Amsterdam status and other criteria (Raptis et al, 2007). Recruitment was preferential for cases with positive familial risk. Apparent cases of familial adenomatous polyposis were excluded. A total of 1004 probands with blood and/or tissue biospecimens were obtained at the time of study accrual. Due to the high prevalence of self-reported Caucasians (92.5\%) and to limit the possible effects of population stratification, we excluded non-white patients and those with unknown or mixed ethnic background. Of the remaining 921 probands, we were able to obtain 600 tumour samples for methylation analysis, representing 561 of these probands. Several probands were subsequently excluded during methylation analysis due to poor quality DNA (see section MethyLight), leading to a final cohort of 545 Ontario cases. Annual follow-up was available for these probands to assess vital status and recurrence.

Case selection at NFCCR was similar to that of OFCCR except for a slightly later recruitment period (1999-2003) and the inclusion of all incident CRC patients irrespective of family history (Green et al, 2007). In addition, for deceased patients, NFCCR accepted proxy consent from living family members, which led to more frequent inclusion of late stage patients. A total of 747 probands were recruited by NFCCR, of which 721 probands were white (northern European origin) and had tumour samples available. Molecular analysis was successfully performed on 687 cases after removal of poor quality samples. An overview of patient clinicopathological features is shown in Table 1.

\section{Molecular analysis}

Tumour and matched normal tissues were collected from surgical specimens and embedded in paraffin. DNA was extracted (after microdissection for Ontario patients, $>70 \%$ cellularity for tumours) and used previously to analyze MSI status, MLH1 methylation levels, and BRAF V600E mutational status.

MSI testing was performed using National Cancer Institute guidelines, as previously described (Raptis et al, 2007). Briefly, five or more markers were analysed from a panel consisting of: ACTC, BAT-25, BAT-26, BAT-40, BAT-34C4, D10S197, D18S55, D2S123, D5S346, and MYC-L. Microsatellite instability status was defined by the number of positive markers as follows: MSI high $(\geqslant 30 \%$ unstable markers), MSI low (1-29\% unstable markers), or microsatellite stable ( $0 \%$ unstable markers). Newfoundland tumours that were initially characterised as MSI low were screened for a second set of markers: BAT-40, D7S519, D17S787, D18S58, and D20S100 (Woods et al, 2005). Due to the limited frequency of MSI low in our population and in conjunction with the classical definition of MSI status, tumours initially classified as MSI low or microsatellite stable were combined and classified as 'MSS'. Microsatellite instability- $\mathrm{H}$ tumours were therefore denoted as 'MSI'. As previously identified (Green et al, 2009), the frequency of MSI tumours in Newfoundland was relatively low (9.9\%), which may be due, in part, to the low frequency of germline mismatch repair mutations (Woods et al, 2005).

Status of $M L H 1$ methylation was assessed by quantitative MethyLight assay as previously described (Mrkonjic et al, 2010). Positive methylation was defined as per cent methylated reference $(\mathrm{PMR})>10$. A large proportion of tumours in Newfoundland $(37.6 \%)$ were not tested due to unavailability of tumour tissue.

The somatic c.1799T $>$ A gene mutation (p. V600E) in the BRAF gene was analysed by allelic discrimination assay, as previously described in Ontario (Rawson et al, 2011) and in Newfoundland (Loughrey et al, 2007). In Ontario, $10 \%$ of samples were validated with $100 \%$ concordance. In Newfoundland, all samples with positive methylation were validated by direct sequencing.

Immunohistochemical staining of mismatch repair proteins MLH1, MSH2, MSH6, and PMS2 was performed by a trained pathologist as previously described (Lindor et al, 2002). Staining was classified as present, absent, or inconclusive. Tumours with absent staining in any of these proteins were defined as mismatch repair deficient.

\section{MethyLight}

Methylation analysis was performed on matched tumour and normal tissue using semi-quantitative MethyLight assay, a Taqmanbased technique that assesses per cent DNA methylation at a single gene locus per reaction (Eads et al, 2000). Sodium bisulphite treatment was performed on $50 \mathrm{ng}$ of sample DNA using EZ DNA Methylation Gold kit (Zymo Research Corp., Orange, CA, USA) according to the manufacturer's protocol. Modified DNA was stored at $-20^{\circ} \mathrm{C}$ until use. Primers and probes were designed to 
Table I Distribution of clinicopathological features, including Wnt5a methylation in primary colorectal carcinomas from Ontario and Newfoundland

No. of cases (\%)

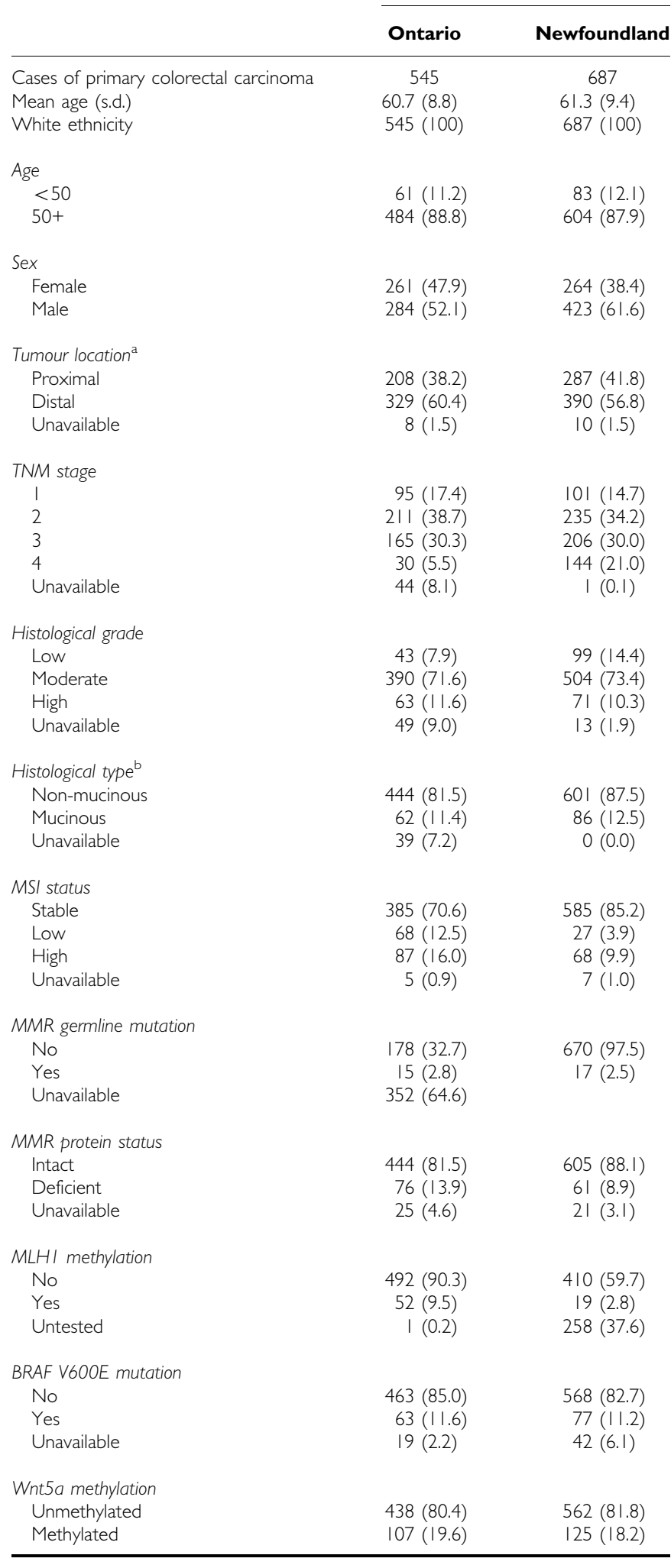

Abbreviations: $\mathrm{BRAF}=\mathrm{v}$-raf murine sarcoma viral oncogene homolog $\mathrm{Bl}$ $\mathrm{MLHI}=$ mutL homolog I; $M M R=$ mismatch repair; $M S I=$ microsatellite instability;

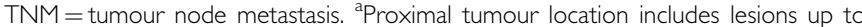
and including the splenic flexure. bMucinous histology includes the presence of any mucin within the tumour stroma. amplify a region within the promoter $\mathrm{CpG}$ island of $W n t 5 a$ as close as possible to regions previously studied by methyl-specific PCR (Mazieres et al, 2004; Ying et al, 2008). We also designed primers and a probe to amplify the genomic repeat sequence $\mathrm{Alu}-\mathrm{C} 4$ to normalise for DNA amount. This is a methylation-independent reaction and minimises amplification bias due to potential sample aneuploidy (Weisenberger et al, 2005). Primer and probe sequences were (Wnt5a forward) $5^{\prime}$-TTT AGG TTC GGG CGT TAG TGT TC $-3^{\prime}$; (Wnt5a reverse) $5^{\prime}$-TCA AAA ACA AAA CTA CGA AAT CCT CC-3'; (Wnt5a probe) 6FAM-5'-TTT AGT TTC GGT TTA TTG CGT TCG TCG GA-3'-MGBNFQ; (ALU-C4 forward) $5^{\prime}$-GGT TAG GTA TAG TGG TTT ATA TTT GTA ATT TTA GTA-3'; (ALU-C4 reverse) $5^{\prime}$-ATT AAC TAA ACT AAT CTT AAA CTC CTA ACC TCA-3'; (ALU-C4 probe) 6FAM-5'-CCT ACC TTA ACC TCC C-3'-MGBNFQ.

Samples were analysed in 96-well plates on an ABI 7500 RT - PCR thermocycler as previously described (Weisenberger et al, 2005). Methylation was calculated as follows (Weisenberger et al, 2006): $\quad \mathrm{PMR}=(\text { gene/Alu-C4 })_{\text {sample }} /(\text { gene/Alu-C4 })_{\mathrm{CpGenome}} \times 100 \%$. CpGenome DNA (Millipore, Billerica, MA, USA) was exogenously methylated lymphocyte DNA that was amplified on each plate to define a $100 \%$ reference signal for each gene. Receiver operator curves were generated from a subset of 100 tumour-matched normal pairs from Ontario to produce a tumour-specific methylation cutoff $(\mathrm{PMR}=10)$. This cutoff was used to define positive methylation and is a conservative value for transcriptional silencing of other genes (Ogino et al, 2006). For cases with multiple DNA samples due to synchronous baseline tumours (ON: $n=34$; NFLD: $n=16$ ), PMR values were averaged.

Validation was performed on randomly selected samples to account for interplate variation. Per cent methylated reference readings during validation tended to fluctuate $<10 \%$ and reassignment of methylation status was exceptionally rare. During screening and validation, samples with an Alu-C4 threshold cycle above 22.0 were considered poor quality, retreated with sodium bisulphite, and subsequently reanalysed to ensure robust amplification. Samples that remained poor quality were removed from the analysis (ON: $n=16$; NFLD: $n=34$ ).

\section{Statistical analysis}

The selectivity of Wnt5a methylation for tumour tissue over matched normal tissue was assessed using McNemar's $\chi^{2}$-test All univariate clinicopathological associations were assessed by Fisher's exact test. Multivariate modelling of MSI status was conducted using unconditional logistic regression adjusted for age, sex, and tumour location. Unadjusted associations to recurrencefree survival status were assessed using Kaplan-Meier analysis with the log-rank test. Multivariate associations to recurrence-free survival status were conducted using a Cox regression model adjusted for age, sex, stage, and grade, with and without MSI status. Time-toevent was calculated from the date of diagnosis to the date of first recurrence/death or censored at the date of last contact. A two-sided $P<0.05$ was considered statistically significant. Bonferroni corrections for multiple comparisons were incorporated, where appropriate. Analysis was performed using SPSS version 16.0 (SPSS Inc., Chicago, IL, USA).

\section{RESULTS}

\section{Methylation analysis}

We quantified promoter methylation levels of the Wnt5a gene in 545 colorectal carcinomas from Ontario and 687 colorectal carcinomas from Newfoundland. Wnt5a was methylated in 107 $(19.6 \%)$ cases in Ontario and $125(18.2 \%)$ cases in Newfoundland (Table 1). To verify that these methylation events were specific to 
tumour tissue, we requantified Wnt5a methylation levels in 53 tumour samples in parallel with their matched normal colonic mucosa samples (oversampling was conducted for positive tumour methylation to increase the number of informative samples). Wnt5a was methylated in 27 of these tumours (17 MSI, 10 MSS) and no methylation was found in matched normal tissue.

\section{Methylation and clinicopathological features}

We examined associations between Wnt5a methylation status and patient clinicopathological features in both populations. In Ontario, Wnt5a methylation was much more common in MSI tumours than in MSS tumours (odds ratio $(\mathrm{OR})=6.3,95 \%$ confidence interval $(\mathrm{CI})=3.9-10.4, P<10^{-12}$ ) (Table 2). This relationship was reflected in associations between $W n t 5 a$ methylation and MSI-associated tumour characteristics, including immunohistochemical deficiency of at least one mismatch repair protein $\left(\mathrm{OR}=7.2,95 \% \mathrm{CI}=4.3-12.2, P<10^{-12}\right)$, MLH1 methylation $\left(\mathrm{OR}=14.9,95 \% \mathrm{CI}=7.8-28.5, P<10^{-16}\right)$, proximal location $\left(\mathrm{OR}=3.6,95 \% \mathrm{CI}=2.3-5.6, P<10^{-7}\right)$, mucinous histological type $(\mathrm{OR}=2.0,95 \% \quad \mathrm{CI}=1.1-3.7, \quad P=0.03)$, and female gender $\left(\mathrm{OR}=2.5,95 \% \mathrm{CI}=1.6-3.8, P<10^{-4}\right)$ (Table 2). There was, however, no association between $W n t 5 a$ methylation and germline mutations in mismatch repair gene, which cause the inherited MSI tumours found in Lynch syndrome $(\mathrm{OR}=0.3,95 \% \mathrm{CI}=0.1-1.6$,
$P=0.24)$. The absence of this association to Lynch-associated MSI tumours was maintained after adjustment for age (data not shown), indicating the absence of confounding effects due to ageassociated methylation. Indeed, Wnt5a methylation was not associated with age $\geqslant 50$ years compared with age $<50$ years $(\mathrm{OR}=1.5,95 \% \mathrm{CI}=0.7-3.1, P=0.39)$. Wnt5a methylation was also strongly associated with $B R A F$ V600E mutation $(\mathrm{OR}=12.3$, $\left.95 \% \mathrm{CI}=6.9-21.7, P<10^{-17}\right)$, a common alteration in MSI and CIMP, and this association remained after adjustment for MSI status $\left(\mathrm{OR}=7.9,95 \% \mathrm{CI}=4.2-14.7, P<10^{-10}\right)$.

An identical analysis was conducted in our validation cohort from Newfoundland. Wnt5a methylation was similarly associated with MSI tumours $\left(\mathrm{OR}=5.0,95 \% \mathrm{CI}=3.0-8.4, P<10^{-18}\right)$ and the same set of MSI-associated characteristics: MMR IHC deficiency $\left(\mathrm{OR}=6.2,95 \% \mathrm{CI}=6.6-10.7, P<10^{-9}\right)$, MLH1 methylation $\left(\mathrm{OR}=36.7,95 \% \mathrm{CI}=10.3-130.4, \quad P<10^{-10}\right)$, proximal location ( $\mathrm{OR}=3.2,95 \% \mathrm{CI}=2.1-4.9, P<10^{-7}$ ), mucinous histological type $(\mathrm{OR}=1.9,95 \% \mathrm{CI}=1.1-3.2, P=0.02)$, and female gender $(\mathrm{OR}=1.6,95 \% \mathrm{CI}=1.1-2.3, P=0.03)$ (Table 2). Wnt5a methylation remained unassociated with age $\geqslant 50$ years $(\mathrm{OR}=1.7$, $95 \% \mathrm{CI}=0.9-3.4, P=0.13$ ), but showed a borderline inverse association with germline MMR gene mutation - no methylated cases carried these mutations, whereas 17 unmethylated cases $(3 \%)$ carried these mutations $(P=0.05)$. Wnt5a methylation also remained strongly associated with $B R A F$ V600E before $(\mathrm{OR}=$

Table 2 Associations between Wnt5a methylation and age, sex, MSI status, MSI-associated features, and BRAF V600E status

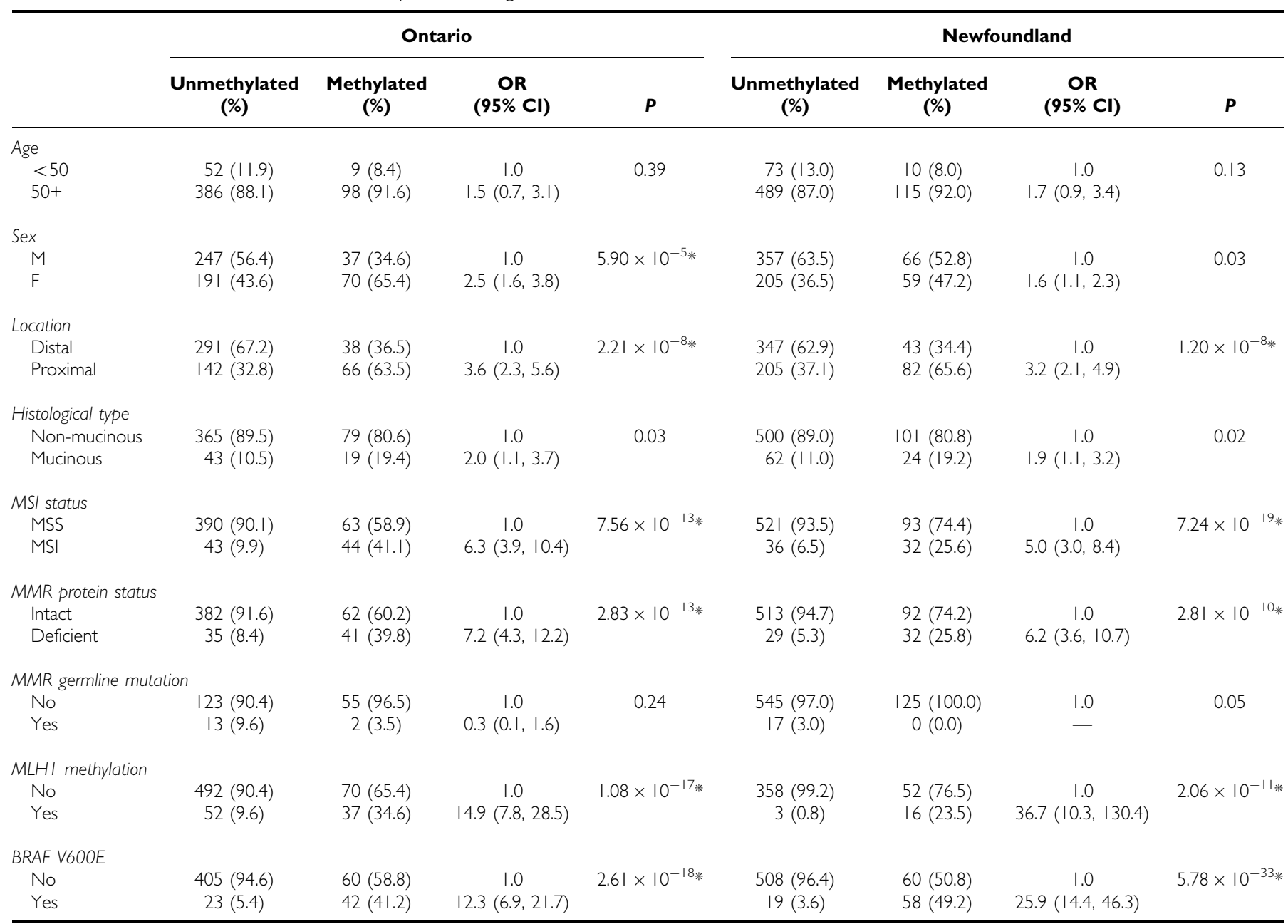

Abbreviations: $\mathrm{BRAF}=\mathrm{v}$-raf murine sarcoma viral oncogene homolog $\mathrm{BI}: \mathrm{Cl}=$ confidence interval; $\mathrm{MMR}=$ mismatch repair; $\mathrm{MSI}=$ microsatellite instability; $\mathrm{MSS}=$ microsatellite stable; $\mathrm{OR}=$ odds ratio; TNM = tumour node metastasis. *Significant $P$-value after Bonferroni correction $\left(P<5.55 \times 10^{-3}\right)$. - OR cannot be computed due to zero cell count. 
Table 3 Multivariate MSI analysis adjusted for age, sex, tumour location, and Wnt5a methylation status

\begin{tabular}{|c|c|c|c|c|c|c|}
\hline \multirow[b]{2}{*}{ Variable } & \multicolumn{3}{|c|}{ Ontario } & \multicolumn{3}{|c|}{ Newfoundland } \\
\hline & Univariate $P$ & Multivariate $P$ & Multivariate OR $(95 \% \mathrm{Cl})$ & Univariate $P$ & Multivariate $P$ & Multivariate OR $(95 \% \mathrm{Cl})$ \\
\hline Female Sex & 0.003 & 0.27 & $1.36(0.79,2.35)$ & 0.05 & 0.31 & $1.33(0.77,2.29)$ \\
\hline Proximal Location & $4.37 \times 10^{-15}$ & $7.82 \times 10^{-12}$ & $8.41(4.57,15.47)$ & $1.31 \times 10^{-12}$ & $7.74 \times 10^{-8}$ & $6.21(3.19,12.09)$ \\
\hline Wnt5a Meth & $7.56 \times 10^{-15}$ & $6.94 \times 10^{-7}$ & $4.22(2.39,7.45)$ & $7.24 \times 10^{-9}$ & $3.94 \times 10^{-6}$ & $3.78(2.15,6.64)$ \\
\hline
\end{tabular}

Abbreviations: $\mathrm{Cl}=$ confidence interval; $\mathrm{MSI}=$ microsatellite instability; $\mathrm{OR}=$ odds ratio

25.9, $\left.95 \% \mathrm{CI}=14.4-46.3, P<10^{-33}\right)$ and after $(\mathrm{OR}=20.9,95 \%$ $\left.\mathrm{CI}=11.4-38.5, P<10^{-21}\right)$ adjustment for MSI status.

Methylation status of Wnt5a was weakly associated or not associated with several other clinicopathological characteristics in one population, including: pathological $\mathrm{N}$ and $\mathrm{M}$ substages, local invasion, patient history of irritable bowel syndrome, and patient history of inflammatory bowel disease (Supplementary Table 1). Notably, however, Wnt5a methylation increased with grade in both populations and trended towards an association with increasing tumour stage and, more specifically, pathological $\mathrm{T}$ substage in Newfoundland (Supplementary Table 1).

\section{Methylation and multivariate MSI}

We constructed a multivariate MSI model to adjust for the possible confounders of age, sex, and tumour location (Table 3). These covariates were each individually associated with MSI status in both populations (data not shown). After adjustment for these factors, Wnt5a methylation remained strongly associated with MSI in both Ontario $\left(\mathrm{OR}=4.2,95 \% \mathrm{CI}=2.4-7.5, P<10^{-6}\right)$ and Newfoundland $\left(\mathrm{OR}=3.8,95 \% \mathrm{CI}=2.2-6.6, P<10^{-5}\right)$.

\section{Methylation and recurrence-free survival}

To assess the prognostic role of Wnt5a methylation, we conducted recurrence-free survival analysis. In Ontario, there were 120 recurrences and/or deaths due to CRC with a mean interval of 30 months from diagnosis. The mean follow-up time among remaining cases was 97 months. Wnt5a methylation was not significantly associated with outcome in unadjusted analysis ( $\mathrm{HR}=0.7,95 \% \mathrm{CI}=0.4-1.1, P=0.13$ ) or after adjustment for age, sex, stage, and grade $(\mathrm{HR}=0.8,95 \% \mathrm{CI}=0.5-1.4, P=0.42)$.

A similar analysis was conducted in Newfoundland, where there were 244 recurrences and/or deaths with a mean interval of 26 months from diagnosis. The mean follow-up time among remaining cases was 65 months. Again, Wnt5a methylation was not associated with outcome in unadjusted analysis $(\mathrm{HR}=1.0,95 \%$ $\mathrm{CI}=0.7-1.4, P=0.83$ ) or after adjustment for age, sex, stage, and grade $(\mathrm{HR}=0.8,95 \% \mathrm{CI}=0.6-1.2, P=0.28)$.

To assess the potential effects of MSI status on these relationships, we verified that MSI was a prognosticator of favourable outcome in both Ontario ( $\mathrm{HR}=0.3,95 \% \mathrm{CI}=0.2-0.7, P=0.002)$ and Newfoundland ( $\mathrm{HR}=0.5,95 \% \mathrm{CI}=0.3-0.8, P=0.007)$ and subsequently added an MSI covariate to the multivariate survival model. After this additional adjustment for MSI status, there was clearly no association between Wnt5a methylation and patient outcome in either Ontario $(\mathrm{HR}=1.0,95 \% \mathrm{CI}=0.6-1.7, P=0.96)$ or Newfoundland $(\mathrm{HR}=0.9,95 \% \mathrm{CI}=0.6-1.3, P=0.53)$.

\section{DISCUSSION}

Wnt5a is emerging as an important functional and prognostic contributor in several cancers and is commonly silenced by promoter hypermethylation. In CRC, DNA methylation has a vital role in defining prognostic subtypes, and aberrant Wnt signalling is critical for carcinogenesis; however, the prevalence of Wnt5a methylation in CRC and its distribution among tumour subtypes is poorly understood. In an effort to determine the frequency of this event between CRC subtypes and its potential prognostic role, we examined Wnt5a promoter methylation levels in two distinct MSIstratified Canadian populations: Ontario, a heterogeneous population with a moderate incidence of CRC, and Newfoundland, a founder population with a high incidence of CRC, particularly within families (Woods et al, 2005). Despite these differences, Wnt5a methylation was concordantly observed in approximately $20 \%$ of tumours from both population. This is a lower methylation frequency than previously reported in two small CRC series from East Asia (Ying et al, 2008; Ahn et al, 2011). Wnt5a methylation was absent from a subset of matched normal mucosa, verifying that this event is tumour specific.

Importantly, this event was unequally distributed among MSI subtypes; Wnt5a methylation was much more common in MSI tumours than in MSS tumours in both populations and these associations were independent of the combined effects of patient age, sex, and tumour location. Furthermore, Wnt5a methylation was strongly associated with $M L H 1$ methylation, the primary cause of sporadic MSI, but not associated with germline MMR gene mutations, which cause the inherited MSI tumours found in Lynch Syndrome. Consequently, Wnt5a appears to be preferentially methylated among sporadic MSI tumours compared with HNPCCassociated MSI tumours.

Wnt5a methylation was also strongly associated with the oncogenic BRAF V600E mutation, a surrogate marker of CIMP high (Ogino and Goel, 2008) that correlates with a distinct subset of CIMP-associated methylation markers (Tanaka et al, 2010). BRAF V600E is an independent prognosticator of poor outcome in CRC and seems to be important confounder to the prognostic roles of CIMP (Kim et al, 2009; Ogino et al, 2009). Combined status of BRAF V600E, CIMP, and MSI has been proposed to more accurately stratify prognostic groups in CRC (Kim et al, 2009; Ogino et al, 2009; Dahlin et al, 2010). The strong and independent associations of Wnt5a methylation with both MSI and BRAF V600E suggest that this event may be a marker of MSI/CIMP-high tumours, which seem to be a particularly favourable CRC subset in these studies. Since promoter methylation of Wnt5a induces transcriptional silencing in CRC cells (Ying et al, 2008), our results suggest that MSI and/or CIMP-high tumours may experience preferential repression of non-canonical Wnt activity. These findings extend our previous results that suggested MSS tumours may be preferentially permissive to non-canonical Wnt stimulation due to the methylation status of Wnt antagonist genes (Rawson et al, 2011). Consequently, multiple epigenetic events may promote differential non-canonical Wnt stimulation between CRC subtypes.

In addition to its effects on non-canonical Wnt activity, Wnt5a is also known to inhibit $\beta$-catenin accumulation in CRC cells (Ying et al, 2008; Yuzugullu et al, 2009), suggesting that MSI and/or CIMP-high tumours may also experience preferential activation of canonical Wnt activity. This may be particularly important during 
development of MSI and CIMP tumours due to the relative absence of APC mutation as a means to induce cytoplasmic $\beta$-catenin accumulation in these tumours (Thorstensen et al, 2005; Samowitz et al, 2007; Albuquerque et al, 2010). Promoter methylation of the $D K K 1$ gene, which encodes a pivotal antagonist of the canonical Wnt pathway, has already been strongly associated with MSI (Rawson et al, 2011), begging the question whether canonical Wnt activity may be primarily driven by upstream epigenetic changes rather than downstream genetic changes in this subset of CRCs. Further investigation of the epigenetic status of other Wnt regulatory genes between CRC subtypes will be necessary to scrutinise this hypothesis.

Despite the attractive downstream effects of Wnt5a on cell signaling, the impact of subtype-associated Wnt5a methylation on subtype-specific CRC outcome is unclear. By offering both tumour-suppressive and oncogenic effects, the opposing regulatory functions of Wnt5a on canonical and non-canonical Wnt pathways may obscure the prognostic role of Wnt5a methylation in our analysis and help explain the conflicting results obtained in other cancers. Indeed, it has been proposed that these discordant functions of Wnt5a may affect CRC prognosis in a time-dependent manner, whereby early Wnt5a expression exerts a favourable effect by inhibiting tumour growth through canonical Wnt suppression, whereby late expression of Wnt5a exerts a deleterious effect by promoting tumour invasion through non-canonical Wnt activation (Wang, 2009). This model is harmonious with the identification of Wnt5a expression as a marker of favourable outcome in early CRC (Dejmek et al, 2005). Since methylation was well represented in both early and late stage tumours within our populations, this may help explain the absence of a significant association to recurrence-free survival despite the strong association to MSI. In addition, the prognostic relevance of Wnt5a methylation may be confounded by the status of downstream canonical and non-canonical Wnt mediators that may influence the signalling response to Wnt5a loss. Importantly, these effects may also be related to tumour subtype since alterations in canonical Wnt components seem to vary with MSI status (Thorstensen et al, 2005; Ortega et al, 2008; Albuquerque et al,

\section{REFERENCES}

Ahn JB, Chung WB, Maeda O, Shin SJ, Kim HS, Chung HC, Kim NK, Issa JP (2011) DNA methylation predicts recurrence from resected stage III proximal colon cancer. Cancer 117(9): 1847- 1854

Albuquerque C, Baltazar C, Filipe B, Penha F, Pereira T, Smits R, Cravo M, Lage P, Fidalgo P, Claro I, Rodrigues P, Veiga I, Ramos JS, Fonseca I, Leitao CN, Fodde R (2010) Colorectal cancers show distinct mutation spectra in members of the canonical WNT signaling pathway according to their anatomical location and type of genetic instability. Genes Chromosomes Cancer 49(8): 746-759

Carethers JM, Smith EJ, Behling CA, Nguyen L, Tajima A, Doctolero RT, Cabrera BL, Goel A, Arnold CA, Miyai K, Boland CR (2004) Use of 5 -fluorouracil and survival in patients with microsatellite-unstable colorectal cancer. Gastroenterology 126(2): 394-401

Dahlin AM, Palmqvist R, Henriksson ML, Jacobsson M, Eklof V, Rutegard J, Oberg A, Van Guelpen BR (2010) The role of the CpG island methylator phenotype in colorectal cancer prognosis depends on microsatellite instability screening status. Clin Cancer Res 16(6): $1845-1855$

Dejmek J, Dejmek A, Safholm A, Sjolander A, Andersson T (2005) Wnt-5a protein expression in primary dukes B colon cancers identifies a subgroup of patients with good prognosis. Cancer Res 65(20): 9142-9146

Eads CA, Danenberg KD, Kawakami K, Saltz LB, Blake C, Shibata D, Danenberg PV, Laird PW (2000) MethyLight: a high-throughput assay to measure DNA methylation. Nucleic Acids Res 28(8): E32

Green RC, Green JS, Buehler SK, Robb JD, Daftary D, Gallinger S, McLaughlin JR, Parfrey PS, Younghusband HB (2007) Very high incidence of familial colorectal cancer in Newfoundland: a comparison with Ontario and 13 other population-based studies. Fam Cancer 6(1): 53-62
2010), although subtype specificity in non-canonical Wnt pathway components has not been explored.

To our knowledge, this is the first study to identify an association between Wnt5a methylation and cancer subtype. These findings extend the perspective that epigenetic events may promote differential Wnt signalling between tumour subtypes. Determining the exact functional and prognostic significant of these events may rely on investigating the collective genetic and epigenetic status of other Wnt mediators in the context of tumour subtype.

\section{ACKNOWLEDGEMENTS}

This work was supported by the National Cancer Institute, National Institutes of Health under RFA \# CA-95-011 and through cooperative agreements with members of the Colon Cancer Family Registry and P.I.s. The content of this manuscript does not necessarily reflect the views or policies of the National Cancer Institute or any of the collaborating centres in the CFRs, nor does mention of trade names, commercial products, or organisations imply endorsement by the US Government or the CFR. This work was also supported by a Team Grant from the Canadian Institutes of Health Research (CTP-79845 awarded to JRM, BB, JAK, SSG, RCG, and PSP) and by funding within the Colon Cancer Familial Registry awarded to the Ontario Registry for Studies of Familial Colorectal Cancer (Grant no. U01 CA074783, Principle Investigator: SSG). JBR was supported by graduate studentships from the Team in Interdisciplinary Research on Colorectal Cancer funded by the Canadian Institutes of Health Research and by graduate studentships from the University of Toronto (open fellowships administered by the Department of Laboratory Medicine and Pathobiology). We sincerely thank the investigators, staff, and participants of the Colon Cancer Family Registry for their dedicated contributions.

Supplementary Information accompanies the paper on British Journal of Cancer website (http://www.nature.com/bjc)

Green RC, Parfrey PS, Woods MO, Younghusband HB (2009) Prediction of Lynch syndrome in consecutive patients with colorectal cancer. J Natl Cancer Inst 101(5): $331-340$

Jonsson M, Dejmek J, Bendahl PO, Andersson T (2002) Loss of Wnt-5a protein is associated with early relapse in invasive ductal breast carcinomas. Cancer Res 62(2): 409-416

Ki DH, Jeung HC, Park CH, Kang SH, Lee GY, Lee WS, Kim NK, Chung HC, Rha SY (2007) Whole genome analysis for liver metastasis gene signatures in colorectal cancer. Int J Cancer 121(9): 2005-2012

Kim JH, Shin SH, Kwon HJ, Cho NY, Kang GH (2009) Prognostic implications of $\mathrm{CpG}$ island hypermethylator phenotype in colorectal cancers. Virchows Arch 455(6): 485-494

Kremenevskaja N, von Wasielewski R, Rao AS, Schofl C, Andersson T, Brabant G (2005) Wnt-5a has tumor suppressor activity in thyroid carcinoma. Oncogene 24(13): 2144-2154

Leris AC, Roberts TR, Jiang WG, Newbold RF, Mokbel K (2005) WNT5A expression in human breast cancer. Anticancer Res 25(2A): $731-734$

Liang H, Chen Q, Coles AH, Anderson SJ, Pihan G, Bradley A, Gerstein R, Jurecic R, Jones SN (2003) Wnt5a inhibits B cell proliferation and functions as a tumor suppressor in hematopoietic tissue. Cancer Cell 4(5): $349-360$

Lindor NM, Burgart LJ, Leontovich O, Goldberg RM, Cunningham JM, Sargent DJ, Walsh-Vockley C, Petersen GM, Walsh MD, Leggett BA, Young JP, Barker MA, Jass JR, Hopper J, Gallinger S, Bapat B, Redston M, Thibodeau SN (2002) Immunohistochemistry vs microsatellite instability testing in phenotyping colorectal tumors. J Clin Oncol 20(4): $1043-1048$ 
Loughrey MB, Waring PM, Tan A, Trivett M, Kovalenko S, Beshay V Young MA, McArthur G, Boussioutas A, Dobrovic A (2007) Incorporation of somatic BRAF mutation testing into an algorithm for the investigation of hereditary non-polyposis colorectal cancer. Fam Cancer 6(3): $301-310$

Martin V, Valencia A, Agirre X, Cervera J, San Jose-Eneriz E, Vilas-Zornoza A, Rodriguez-Otero P, Sanz MA, Herrera C, Torres A, Prosper F, Roman-Gomez J (2010) Epigenetic regulation of the non-canonical Wnt pathway in acute myeloid leukemia. Cancer Sci 101(2): 425-432

Mazieres J, He B, You L, Xu Z, Lee AY, Mikami I, Reguart N, Rosell R, McCormick F, Jablons DM (2004) Wnt inhibitory factor-1 is silenced by promoter hypermethylation in human lung cancer. Cancer Res 64(14): $4717-4720$

Mrkonjic M, Roslin NM, Greenwood CM, Raptis S, Pollett A, Laird PW, Pethe VV, Chiang T, Daftary D, Dicks E, Thibodeau SN, Gallinger S, Parfrey PS, Younghusband HB, Potter JD, Hudson TJ, McLaughlin JR, Green RC, Zanke BW, Newcomb PA, Paterson AD, Bapat B (2010) Specific variants in the MLH1 gene region may drive DNA methylation, loss of protein expression, and MSI-H colorectal cancer. PLoS One 5(10): e13314

Newcomb PA, Baron J, Cotterchio M, Gallinger S, Grove J, Haile R, Hall D, Hopper JL, Jass J, Le Marchand L, Limburg P, Lindor N, Potter JD, Templeton AS, Thibodeau S, Seminara D (2007) Colon cancer family registry: an international resource for studies of the genetic epidemiology of colon cancer. Cancer Epidemiol Biomarkers Prev 16(11): $2331-2343$

Ogino S, Goel A (2008) Molecular classification and correlates in colorectal cancer. J Mol Diagn 10(1): 13-27

Ogino S, Kawasaki T, Brahmandam M, Cantor M, Kirkner GJ, Spiegelman D, Makrigiorgos GM, Weisenberger DJ, Laird PW, Loda M, Fuchs CS (2006) Precision and performance characteristics of bisulfite conversion and real-time PCR (MethyLight) for quantitative DNA methylation analysis. J Mol Diagn 8(2): 209-217

Ogino S, Nosho K, Kirkner GJ, Kawasaki T, Meyerhardt JA, Loda M, Giovannucci EL, Fuchs CS (2009) CpG island methylator phenotype, microsatellite instability, BRAF mutation and clinical outcome in colon cancer. Gut 58(1): $90-96$

Ortega P, Moran A, de Juan C, Frias C, Hernandez S, Lopez-Asenjo JA, Sanchez-Pernaute A, Torres A, Iniesta P, Benito M (2008) Differential Wnt pathway gene expression and E-cadherin truncation in sporadic colorectal cancers with and without microsatellite instability. Clin Cancer Res 14(4): $995-1001$

Raptis S, Mrkonjic M, Green RC, Pethe VV, Monga N, Chan YM, Daftary D, Dicks E, Younghusband BH, Parfrey PS, Gallinger SS, McLaughlin JR, Knight JA, Bapat B (2007) MLH1 -93G > A promoter polymorphism and the risk of microsatellite-unstable colorectal cancer. J Natl Cancer Inst 99(6): $463-474$

Rawson J, Mrkonjic M, Darshana D, Dicks E, Buchanan D, Younghusband H, Parfrey P, Young J, Green R, Pollett A, Gallinger S, McLaughlin J, Knight J, Bapat B (2011) Promoter methylation of Wnt antagonists DKK1 and SFRP1 are associated with opposing tumor subtypes in a large cohort of colorectal cancer. Carcinogenesis, e-pub ahead of print 8 February 2011

Ribic CM, Sargent DJ, Moore MJ, Thibodeau SN, French AJ, Goldberg RM, Hamilton SR, Laurent-Puig P, Gryfe R, Shepherd LE, Tu D, Redston M, Gallinger S (2003) Tumor microsatellite-instability status as a predictor of benefit from fluorouracil-based adjuvant chemotherapy for colon cancer. N Engl J Med 349(3): 247-257

Samowitz WS, Slattery ML, Sweeney C, Herrick J, Wolff RK, Albertsen H (2007) APC mutations and other genetic and epigenetic changes in colon cancer. Mol Cancer Res 5(2): 165-170

Tanaka N, Huttenhower C, Nosho K, Baba Y, Shima K, Quackenbush J, Haigis KM, Giovannucci E, Fuchs CS, Ogino S (2010) Novel application of structural equation modeling to correlation structure analysis of $\mathrm{CpG}$ island methylation in colorectal cancer. Am J Pathol 177(6): 2731 - 2740

Thorstensen L, Lind GE, Lovig T, Diep CB, Meling GI, Rognum TO Lothe RA (2005) Genetic and epigenetic changes of components affecting the WNT pathway in colorectal carcinomas stratified by microsatellite instability. Neoplasia 7(2): 99-108

Wang Q, Symes AJ, Kane CA, Freeman A, Nariculam J, Munson P Thrasivoulou C, Masters JR, Ahmed A (2010) A novel role for Wnt/Ca2+ signaling in actin cytoskeleton remodeling and cell motility in prostate cancer. PLoS One 5(5): e10456

Wang Q, Williamson M, Bott S, Brookman-Amissah N, Freeman A, Nariculam J, Hubank MJ, Ahmed A, Masters JR (2007) Hypomethylation of WNT5A, CRIP1 and S100P in prostate cancer. Oncogene 26(45): $6560-6565$

Wang Y (2009) Wnt/Planar cell polarity signaling: a new paradigm for cancer therapy. Mol Cancer Ther 8(8): 2103-2109

Weeraratna AT, Jiang Y, Hostetter G, Rosenblatt K, Duray P, Bittner M, Trent JM (2002) Wnt5a signaling directly affects cell motility and invasion of metastatic melanoma. Cancer Cell 1(3): 279-288

Weisenberger DJ, Campan M, Long TI, Kim M, Woods C, Fiala E, Ehrlich M, Laird PW (2005) Analysis of repetitive element DNA methylation by MethyLight. Nucleic Acids Res 33(21): 6823-6836

Weisenberger DJ, Siegmund KD, Campan M, Young J, Long TI, Faasse MA, Kang GH, Widschwendter M, Weener D, Buchanan D, Koh H, Simms L, Barker M, Leggett B, Levine J, Kim M, French AJ, Thibodeau SN, Jass J, Haile R, Laird PW (2006) CpG island methylator phenotype underlies sporadic microsatellite instability and is tightly associated with BRAF mutation in colorectal cancer. Nat Genet 38(7): $787-793$

Woods MO, Hyde AJ, Curtis FK, Stuckless S, Green JS, Pollett AF Robb JD, Green RC, Croitoru ME, Careen A, Chaulk JA, Jegathesan J, McLaughlin JR, Gallinger SS, Younghusband HB, Bapat BV, Parfrey PS (2005) High frequency of hereditary colorectal cancer in Newfoundland likely involves novel susceptibility genes. Clin Cancer Res 11(19 Part 1): $6853-6861$

Yamamoto H, Oue N, Sato A, Hasegawa Y, Yamamoto H, Matsubara A, Yasui W, Kikuchi A (2010) Wnt5a signaling is involved in the aggressiveness of prostate cancer and expression of metalloproteinase. Oncogene 29(14): 2036-2046

Ying J, Li H, Yu J, Ng KM, Poon FF, Wong SC, Chan AT, Sung JJ, Tao Q (2008) WNT5A exhibits tumor-suppressive activity through antagonizing the Wnt/beta-catenin signaling, and is frequently methylated in colorectal cancer. Clin Cancer Res 14(1): 55-61

Yuzugullu H, Benhaj K, Ozturk N, Senturk S, Celik E, Toylu A, Tasdemir N, Yilmaz M, Erdal E, Akcali KC, Atabey N, Ozturk M (2009) Canonical Wn signaling is antagonized by noncanonical Wnt5a in hepatocellular carcinoma cells. Mol Cancer 8: 90 